Discussion Paper No. 13-111

\title{
Sequential Identification of
} Technological News Shocks

Atılım Seymen

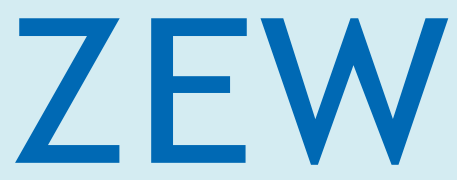

Zentrum für Europäische Wirtschaftsforschung $\mathrm{GmbH}$

Centre for European Economic Research 
Discussion Paper No. 13-111

\title{
Sequential Identification of Technological News Shocks
}

\author{
Atılım Seymen
}

Download this ZEW Discussion Paper from our ftp server:

http://ftp.zew.de/pub/zew-docs/dp/dp13111.pdf

Die Discussion Papers dienen einer möglichst schnellen Verbreitung von neueren Forschungsarbeiten des ZEW. Die Beiträge liegen in alleiniger Verantwortung der Autoren und stellen nicht notwendigerweise die Meinung des ZEW dar.

Discussion Papers are intended to make results of ZEW research promptly available to other economists in order to encourage discussion and suggestions for revisions. The authors are solely responsible for the contents which do not necessarily represent the opinion of the ZEW. 


\title{
Sequential Identification of Technological News Shocks*
}

\author{
Atılım Seymen ${ }^{\dagger}$
}

December 13, 2013

\begin{abstract}
In an influential recent paper, Beaudry and Portier (2006) propose a sequential approach for identifying technological news shocks. Thereby, the correlation coefficient between news shocks of a short-run identification scheme and technology shocks of a long-run identification scheme in the VAR framework measures the extent to which news incorporated into forward-looking variables could reflect future technological developments. While structural VARs can potentially provide a useful guide for modelers as well as policy-makers, the ability of such models to recuperate structural shocks in general and news shocks in particular from the data is a contentious issue in the literature. In the current paper, I find by means of Monte Carlo simulations that the sequential approach can be quite successful in recuperating technological news shocks from artificial data.
\end{abstract}

JEL classification: E32, C32

Keywords: News Shocks; Identification; Structural Vector Autoregressive Model

* This paper is the result of a project sponsored within the scope of the SEEK research program at ZEW Mannheim. I thank Patrick Fève, Ahmat Jidoud, Johannes Pfeifer and Franck Portier for helpful comments and suggestions on earlier drafts. The work also benefited from participation at the 2012 Birmingham Econometrics and Macroeconomics Conference, 3rd Conference on Recent Developments in Macroeconomics at ZEW, and 2012 EEA Conference in Máalaga. Any errors are my own.

$\dagger$ Address: Centre for European Economic Research (ZEW), P.O. Box 103443, D-68304 Mannheim, Germany. E-mail: seymen@zew.de. 


\section{Introduction}

In an influential recent study, Beaudry and Portier (2006; henceforth BP) argue that anticipated technology shocks - labelled news shocks in the following - may be the most important driver of US business cycles. Other authors such as Haertel and Lucke (2008) and Vukotić (2013) also come to this conclusion by applying the empirical technique of BP to German and sectoral US data, respectively. The quality of this empirical finding is important because, if correct, it has serious implications for both theoretical modelling and policy makers. For macroeconomic theoreticians the finding implies a modelling of TFP different than in the conventional framework, for example. An important policy implication-if news shocks are an important driver of business cycles and policy makers ignore them-is, on the other hand, that they may run the risk of interpreting some recessions as resulting from negative demand shocks, while these are in fact only due to problems related to not anticipating the future correctly. In such a case, stabilization policy through demand management could have, contrary to the aim of the policy, destabilizing effects on the economy.

The point of departure of BP's empirical analysis is a reduced-form cointegrated vector autoregressive (VAR) model comprising total factor productivity (TFP) and a stock price (SP) index - a forward-looking variable. BP sequentially apply two different identification schemes on the VAR, labelled short-run (SR) and long-run (LR) schemes in the following, which both orthogonalize the structural shocks and normalize their variance to unity, but differ in the formulation of the additional restriction that is necessary for an exact identification. The long-run scheme imposes the restriction that only the first shock of the system has a long-run effect on TFP, and that shock is therefore labelled as a technology shock, in line with the conventional wisdom. The short-run scheme imposes, on the other hand, the restriction that the second shock in the system, labelled news shock, has no impact effect on TFP but may change it in the longer run and is at the same time reflected by the stock price index contemporaneously. According to the empirical estimates of BP with the US data, the technology shock of the LR scheme and the news shock of the SR scheme are strongly correlated, which leads the authors to conclude that news shocks reflect expected long-run changes in TFP. When the bivariate system is augmented with further variables 
reflecting economic activity, the authors find that these strongly correlated shocks explain an important portion of cyclical fluctuations.

The empirical approach of BP is motivated by the presumption that agents might anticipate permanent improvements in TFP before these are realized and that this anticipation might be reflected by forward-looking variables such as stock prices. As noted above, the authors check the validity of their presumption by evaluating a correlation coefficient empirically by means of structural VARs. It is, however, known that SVARs with news shocks are typically subject to the so-called non-invertibility problem which is said to exist when there is no (perfect) mapping between the VAR representation of observable variables and the structural shocks of a theoretical model ${ }^{1}$, as shown by e.g., Schmitt-Grohé (2009), Fève, Matheron, and Sahuc (2009), Leeper, Walker, and Yang (2009), Fève and Jidoud (2012) and Sims (2012).

Fève and Jidoud (2012) show that the non-invertibility problem is closely related to the degree of the forward-looking dimension of the variables included in the VAR as well as the relative size of news shocks. While SVARs may perform reasonably well even in case of non-invertibility according to their results, the analysis of Fève and Jidoud (2012) relies on a very simple data generating process (DGP) in order to make analytic conclusions possible and they consider only bivariate VARs. Sims (2012) and Forni, Gambetti, and Sala (2011) have also recently argued that the non-invertibility problem may not always be so severe, particularly when a large enough number of (forward-looking) variables are included in the VAR. That is, however, not the practice followed by BP. Moreover, the so-called curse-ofdimensionality problem prevents researchers from including a large number of variables in conventional VARs as argued by, e.g., Beaudry, Portier, and Seymen (2013) recently. Given this background, it appears necessary to investigate the reliability of the BP approach in technological news shock identification with small VARs.

Another relevant issue for the sequential BP approach to news shock identification is, as discussed by Christiano, Eichenbaum, and Vigfusson (2007) in another context, that LR and SR schemes can in general perform differently in identifying the same type of structural shock. It is therefore of interest whether both BP schemes have similar sampling properties

\footnotetext{
${ }^{1}$ See, e.g., Fernández-Villaverde, Rubio-Ramírez, Sargent, and Watson (2007).
} 
and how often they can recuperate the (almost) "true" shocks despite the non-invertibility problem. Fève and Jidoud (2012) show that the performance of the two schemes may differ, even when the non-invertibility problem is not relevant. However, their results rely on a too simple DGP and only bivariate VARs. I discuss the goodness of the BP approach to technological news shock identification by means of Monte Carlo simulations that rely on a more complex DGP in this paper and consider, in addition to a bivariate VAR, trivariate and four-variable VARs à la Beaudry and Portier (2006) as well. Moreover, Fève and Jidoud (2012) consider only one specific TFP specification, whereas I evaluate various possible alternatives that are often used in the macroeconomic literature.

Monte Carlo simulations have been used extensively in recent studies such as Barsky and Sims (2011), Sims (2012) and Beaudry, Portier, and Seymen (2013). The latter two studies involve, in particular, the evaluation of the SR scheme of BP. The current study differs from them with its focus being on the comparison of the SR and LR schemes of BP and on the extent to which the correlation diagnostic test - as it has been dubbed by Fève and Jidoud (2012) — of BP is a useful tool for exploring whether and to what extent news shocks comprise a technological component.

A striking finding of Beaudry and Portier (2006) is the very strong correlation between long-run technology shocks and news shocks. I find that the BP approach is a useful tool for evaluating whether the news shocks have technological content, although SVARs lead to partly spurious results: the BP approach obtains a high correlation between long-run technology shocks and news shocks when the true DGP is constructed in that way and, as importantly, it would not generate a high correlation between the two types of shocks, were they not strongly or not at all correlated in reality.

The paper is organized as follows. In the next section, I describe the sequential technological news shock identification approach of BP. In Section 3, I discuss to what extent the sequential approach could yet approximate the true DGP. Section 4 provides concluding remarks. 


\section{Beaudry-Portier (2006) Framework}

\subsection{Theoretical Framework}

Consider the Cobb-Douglas production technology

$$
Y_{t}=T F P_{t} K_{t-1}^{\theta} N_{t}^{1-\theta}
$$

where $Y_{t}, K_{t}, N_{t}$ and $T F P_{t}$ stand for output, capital stock, labor input and total factor productivity respectively and $0<\theta<1$. The original BP approach to news shocks can be motivated with the TFP specification

$$
T F P_{t}=X_{t} A_{t}
$$

where $X_{t}$ and $A_{t}$ respectively represent the temporary and the permanent component of TFP and are defined as

$$
\log X_{t}=\rho_{X} \log X_{t-1}+\varepsilon_{t}^{X} \quad \text { and } \quad \log A_{t}=\gamma_{A}+\log A_{t-1}+\varepsilon_{t-q}^{n, A}
$$

with $\rho_{X}<1, \gamma_{A}>1 . \varepsilon_{t}^{X}$ and $\varepsilon_{t-q}^{n, A}$ stand for surprise technology and anticipated technologynews - shocks with temporary and permanent effects on TFP, respectively, where perfect foresight is assumed for news shocks for ease of presentation. ${ }^{2}$ In the standard dynamic stochastic general equilibrium framework with rational expectations, which constitutes a workhorse framework for many macroeconomists, news shocks do not impact on the TFP in the $q$ periods after they become known but can change the other variables in the system in the period in which they occur. Thus, if (1) and (2) represent the true TFP dynamics, any structural bivariate moving average representation of TFP and, say, stock price in logs such

\footnotetext{
${ }^{2}$ Note that BP motivate their approach with a Lucas' tree type of model where the TFP specification looks somewhat different. Yet, the TFP specification they consider also comprises (temporary) surprise technology and (permanent) anticipated technology shocks, which is the only crucial point for the forthcoming discussion.
} 


$$
\left[\begin{array}{c}
\Delta t f p_{t} \\
\Delta s p_{t}
\end{array}\right]=\Phi(L) \varepsilon_{t}^{\text {model }}
$$

where $\Delta$ is the difference operator, $\Phi(L)$ is a matrix polynomial with $L$ being the lag operator, should ideally imply

$$
\Phi(1)=\left[\begin{array}{ll}
* & 0 \\
* & *
\end{array}\right] \text { and } \Phi(0)=\left[\begin{array}{ll}
0 & * \\
* & *
\end{array}\right]
$$

and $\varepsilon_{t}^{\text {model }}$ stands for the vector of structural innovations $\varepsilon_{t}^{X}$ and $\varepsilon_{t}^{n, A} \cdot 3,4$ Obviously, the first shock in $\varepsilon_{t}^{\text {model }}$ is one with no contemporaneous impact on TFP, but is the sole driver of it in the long run. The second shock in $\varepsilon_{t}^{\text {model }}$, on the other hand, can have only a short-run impact on TFP which dies out in the long run. These features of the log TFP are in line with the specification given by (1) and (2).

\subsection{Empirical Framework}

\subsubsection{General Framework}

BP estimate bivariate, trivariate and four-variable VECMs with real data that all include TFP $\left(t f p_{t}\right)$ and stock prices $\left(s p_{t}\right)$ as the (first) two variables of the system. The corresponding reduced-form Wold representation is given by

$$
\Delta x_{t}=C(L) \mu_{t}
$$

where $x_{t}$ is the vector of endogenous variables, $C(L)=I+\sum_{i=1}^{\infty} C_{i} L_{i}$, and $\mu_{t}$ is the vector of error terms with the covariance matrix $\Omega .{ }^{5}$ The underlying VECM is always estimated

\footnotetext{
${ }^{3}$ Note that I assume the existence of only two shocks in the DSGE model with respect to the system described by (3) and (4) for ease of presentation.

${ }^{4}$ I assume the stability of the DSGE model when the variables of the model that are growing due to the permanent component $\log A_{t}$ of the $\log$ total factor productivity $\log T F P_{t}$ are transformed into stationary variables. Then, the log-linearized DSGE model has a state-space representation from which a movingaverage representation of the variables as in (3) can be deduced.

${ }^{5}$ The drift term is neglected for ease of presentation.
} 
with $K-1$ cointegrating relationships, $K$ indicating the number of endogenous variables in the system, for which BP find evidence by employing the Nyblom-Harvey test. ${ }^{6}$ BP extract "structural" shocks from this system by working with two alternative representations of (5):

$$
\begin{aligned}
\Delta x_{t} & =\Gamma(L) \varepsilon_{t}, \\
\Delta x_{t} & =\tilde{\Gamma}(L) \tilde{\varepsilon}_{t},
\end{aligned}
$$

with $\Gamma(L)=\sum_{i=0}^{\infty} \Gamma_{i} L_{i}$ and $\tilde{\Gamma}(L)=\sum_{i=0}^{\infty} \tilde{\Gamma}_{i} L_{i}$. The covariance matrices of the structural shocks, $\varepsilon_{t}$ and $\tilde{\varepsilon}_{t}$, are set to be identity matrices following the widespread convention of the SVAR literature. The equivalence of (5), (6) and (7) and the restriction on the covariance matrices of $\varepsilon_{t}$ and $\tilde{\varepsilon}_{t}$ imply that

$$
\begin{gathered}
\mu_{t}=\Gamma_{0} \varepsilon_{t}=\tilde{\Gamma}_{0} \tilde{\varepsilon}_{t}, \\
\Omega=\Gamma_{0} \Gamma_{0}^{\prime}=\tilde{\Gamma}_{0} \tilde{\Gamma}_{0}^{\prime}, \\
\Gamma_{i}=C_{i} \Gamma_{0} \text { and } \tilde{\Gamma}_{i}=C_{i} \tilde{\Gamma}_{0} \text { for } i \geq 0 .
\end{gathered}
$$

The so-called identification problem for the representations in (6) and (7) amounts to the determination of $\Gamma_{0}$ and $\tilde{\Gamma}_{0}$, respectively. Once these matrices are known, one can capture the dynamic multipliers $\Gamma_{i}$ and $\tilde{\Gamma}_{i}$ as well as the structural shocks $\varepsilon_{t}$ and $\tilde{\varepsilon}_{t}$.

Two important properties of systems considered by BP are stated by the following two propositions, which will prove to be useful for my forthcoming discussion. The proofs of the propositions can be found in the appendix. Note that I follow the definition of Lütkepohl (2005), who does not define the cointegration relationship as necessarily one among $I(1)$ variables, in the following. This serves to simplify the presentation, but does not have an impact on my conclusions. ${ }^{7}$

Proposition 1 Let (5) be the Wold representation of a $K$-dimensional I (1) process $x_{t}$ with $r$ cointegrating relationships and ( 7$)$ be its structural representation. If $K-r$ elements of the $j^{\text {th }}$ column of $\tilde{\Gamma}(1)$ are equal to zero, then the remaining elements in the same column

\footnotetext{
${ }^{6}$ This cointegration rank is also in line with standard macroeconomic theory which contains only one unit root due to TFP and in which hours worked is a stationary series. See the discussion below.

${ }^{7}$ I deal with the so-called $I(1)$ processes - processes integrated of order one - in this paper.
} 
are also equal to zero.

Proposition 2 Let (5) be the Wold representation of a $K$-dimensional I (1) process $x_{t}$ with $r$ cointegrating relationships and (7) be its structural representation. Furthermore, let the last $r$ columns of $\tilde{\Gamma}(1)$ comprise a $K \times r$ block of zeros. At most $(K-r)(K-r-1) / 2$ restrictions on $\tilde{\Gamma}_{0}$, in addition to the assumption of the identity covariance matrix of structural shocks, are necessary for an exact identification of the first $K-r$ columns of $\tilde{\Gamma}(1)$.

\subsubsection{Short-Run and Long-Run Schemes}

Bivariate System Since $\Gamma_{0}$ and $\tilde{\Gamma}_{0}$ are $2 \times 2$ matrices in the bivariate case, four restrictions are necessary for a unique identification of their elements. The relationships in (9) provide three restrictions due to the symmetry of the covariance matrix $\Omega$. The difference between the representations (6) and (7) comes from the one additional restriction which is necessary for an exact identification of $\Gamma_{0}$ and $\tilde{\Gamma}_{0}$. The representation in (6) is based on a short-run restriction, namely that the $(1,2)$ element of $\Gamma_{0}$ is equal to zero. The additional restriction for the identification of $(7)$ is a long-run restriction, namely that the $(1,2)$ element of $\tilde{\Gamma}(1)$ is equal to zero. Formally,

$$
\Gamma_{0}=\left[\begin{array}{ll}
* & 0 \\
* & *
\end{array}\right] \text { and } \tilde{\Gamma}(1)=\left[\begin{array}{cc}
* & 0 \\
* & *
\end{array}\right]
$$

where the asterisks show the unrestricted elements of the corresponding matrices. Note that under the $\log$ TFP process given by (1) and (2), $\varepsilon_{2 t}$ and $\tilde{\varepsilon}_{1 t}$ must be identical if both SR and LR identification schemes described by (11) function perfectly.

Higher Dimensional Systems BP examine the correlation between the estimates of $\varepsilon_{2, t}$ and $\tilde{\varepsilon}_{1, t}$ from the bivariate model that are computed with the US data and obtain a high positive correlation between the two shocks. In order to check the robustness of their results and to measure the impact of technological news shocks on other macroeconomic quantities, the authors increase the dimension of the bivariate model first with consumption $\left(c_{t}\right)$ such that $x_{t}=\left[t f p_{t}, s p_{t}, c_{t}\right]^{\prime}$ and then further with investment $\left(i_{t}\right)$ such that $x_{t}=$ 
$\left[t f p_{t}, s p_{t}, c_{t}, i_{t}\right]^{\prime}$. As before, a reduced form representation of the type in (5) underlies two different structural identification schemes, a short-run identification scheme and a long-run identification scheme. ${ }^{8}$ Moreover, the three- and four-variable models are estimated with two and three cointegrating relationships, respectively. ${ }^{9}$ The structural shocks are assumed to have the identity matrix as the covariance matrix as before. The short-run and long-run identification schemes of the trivariate framework are characterised by the restrictions

$$
\Gamma_{0}=\left[\begin{array}{ccc}
* & 0 & 0 \\
* & * & * \\
* & * & *
\end{array}\right] \text { and } \Gamma(1)=\left[\begin{array}{ccc}
* & * & 0 \\
* & * & * \\
* & * & *
\end{array}\right]
$$

and

$$
\tilde{\Gamma}(1)=\left[\begin{array}{ccc}
* & 0 & 0 \\
* & * & * \\
* & * & *
\end{array}\right]
$$

respectively. The four-variable versions of (12) and (13) are

$$
\Gamma_{0}=\left[\begin{array}{cccc}
* & 0 & 0 & 0 \\
* & * & * & 0 \\
* & * & * & * \\
* & * & * & *
\end{array}\right] \text { and } \Gamma(1)=\left[\begin{array}{cccc}
* & * & 0 & 0 \\
* & * & * & * \\
* & * & * & * \\
* & * & * & *
\end{array}\right]
$$

and

$$
\tilde{\Gamma}(1)=\left[\begin{array}{cccc}
* & 0 & 0 & 0 \\
* & * & * & * \\
* & * & * & * \\
* & * & * & *
\end{array}\right] .
$$

Obviously, for the trivariate/four-variable systems to function properly, there must be

\footnotetext{
${ }^{8}$ Notice that conventional VARs postulate the same number of shocks as the number of variables. In the higher dimensional systems, it is trivial to add additional shocks that do not impact on TFP to the data generating process. An example of this can be found in the next section.

${ }^{9}$ Note that this is in line with standard theory where TFP is a unit root process. Adding $c_{t}$ and $i_{t}$ generates additional cointegrating relations between $t f p_{t}$ and $c_{t}$ and $t f p_{t}$ and $i_{t}$, c.f. King, Plosser, and Rebelo (1988b).
} 
additional shocks in the system with no impact effect on TFP but other variables. Note furthermore that in the SR schemes summarized by (12) and (14), two permanent shocks on TFP are allowed now. If (1) and (2) represent the true DGP process, however, then the $(1,1)$ element of $\tilde{\Gamma}(1)$ must be estimated to be zero by both trivariate and four-variable models if these obtain the true dynamics implied by the DGP correctly.

For the systems described by (11),(13) and (15) with a cointegration rank of $K-1$, Proposition 1 implies that the structural long-run multiplier matrix has the form

$$
\tilde{\Gamma}(1)=\left[\begin{array}{cccc}
* & 0 & \cdots & 0 \\
\vdots & \vdots & \ddots & \vdots \\
* & 0 & \cdots & 0
\end{array}\right]
$$

In other words, one zero restriction on a column of the long-run multiplier matrix of a $K$ variable VAR with a cointegration rank of $K-1$ implies that the whole column corresponding to the zero restriction consists of zeros. Thus, (11),(13) and (15) are systems in which only the first shock can have a long-run impact on the variables of the system and the remaining shocks can only have transitory effects on the variables. The only shock with a long-run impact on TFP (as well as other variables) is interpreted to be a technology shock in conventional macroeconomic models as well as in the above described theoretical framework.

The implication of Proposition 2 for the systems (11), (13) and (15), for which $r=K-1$ holds, is that no further restrictions are necessary for the identification of the first column of $\tilde{\Gamma}(1)$. The assumptions of the diagonal covariance matrix of structural shocks with ones on its diagonal and that all $(1, j)$ elements of $\tilde{\Gamma}(1)$ for $j=2, \ldots, K$ are equal to zero suffice to guarantee the identification of the permanent shock. The computation can be carried out following the lines of King, Plosser, Stock, and Watson (1991; henceforth KPSW).

\subsection{The Correlation Diagnostic Test}

Assume that (1) and (2) represent the true DGP and both SR and LR schemes can recover the true news shock from the data generated by that DGP perfectly. In other words, we abstract from various problems that can limit the success of SVAR identification 
schemes such as lag truncation bias, small sample bias etc. that have been discussed in the literature. ${ }^{10}$ In that case, it is to be expected that $\varepsilon_{2, t}, \tilde{\varepsilon}_{1, t}$ and $\varepsilon_{t}^{n, A}$ are perfectly correlated. Yet, even if such problems related to SVAR identification are not relevant, the problem of non-invertibility, which arises when the anticipation lead of the news shocks is more than one period as has been shown by Fève and Jidoud (2012) and Sims (2012), hinders the existence of a perfect correlation between the true shock, $\varepsilon_{t}^{n, A}$, and the estimated shocks, $\varepsilon_{2, t}$ and $\tilde{\varepsilon}_{1, t}$. Nevertheless, as Fève and Jidoud (2012) and Sims (2012) argue, SVARs can still deliver gut approximations of the true DGP, in case forward-looking variables entering the VAR contain sufficient information.

The specification in (1) and (2) thus corresponds to a situation, in which the BP diagnostic test would function perfectly in case the non-invertibilty problem and other problems related to SVAR estimation are irrelevant. However, other TFP specifications are also easily conceivable. Assume, for example, that (1) is defined by

$$
X_{t}=1 \quad \text { and } \quad \log A_{t}=\gamma_{A}+\log A_{t-1}+\varepsilon_{t}^{s, A}+\varepsilon_{t-q}^{n, A}
$$

so that TFP is subject only to permanent surprise and anticipated technology shocks. ${ }^{11}$ In such a setting, when both schemes function perfectly, the SR and LR schemes are expected to recuperate

$$
\varepsilon_{2 t}=\varepsilon_{t-q}^{n, A} \text { and } \tilde{\varepsilon}_{1, t}=\varepsilon_{t}^{s, A}+\varepsilon_{t-q}^{n, A}
$$

so that the correlation between $\varepsilon_{2, t}$ and $\tilde{\varepsilon}_{1, t}$ would be

$$
\operatorname{corr}\left(\varepsilon_{2, t}, \tilde{\varepsilon}_{1, t}\right)=\frac{\sigma_{\varepsilon^{n, A}}^{2}}{\sigma_{\varepsilon^{n, A}} \sqrt{\sigma_{\varepsilon^{s, A}}^{2}+\sigma_{\varepsilon^{n, A}}^{2}}},
$$

where $\sigma_{x}^{2}$ shows the variance of the generic variable $x$. Thus, the true correlation between the estimated shocks from the SR and LR schemes depend on the size of surprise and anticipated

\footnotetext{
${ }^{10}$ See, e.g., Erceg, Guerrieri, and Gust (2005), Christiano, Eichenbaum, and Vigfusson (2007) and Chari, Kehoe, and McGrattan (2008), which explore the ability of SVARs to recuperate true structural shocks and their true multipliers.

${ }^{11}$ The identification schemes of Beaudry and Lucke (2010) and Barsky and Sims (2011) are motivated with such a TFP process.
} 
technology shocks and is less than one.

\section{Monte Carlo Exercises}

BP obtain a strong correlation between the empirical estimates of news and long-run technology shocks in bivariate as well as higher-dimensional systems with the US data. The dynamics invoked by these shocks are also very similar across the LR and SR identification schemes. In order to investigate the use of the sequential approach of BP, I perform several Monte Carlo exercises in this section. I am particularly interested in showing (i) how the SR and LR schemes perform and whether their performance is different and (ii) the extent to which the correlation diagnostic test is a useful tool for recuperating the technology content of news shocks.

\subsection{Data Generating Process}

The DGP that is taken to be an RBC model with two real frictions - internal habit formation in consumption and investment adjustment costs - similar to Barsky and Sims (2011). Note that this model does not produce aggregate comovement across consumption, investment, output and hours in response to news shocks and, hence, deviates from the empirical findings of BP, who find that news shocks should induce aggregate comovement in the data. Therefore, using the RBC model with real frictions as DGP indirectly provides a means to test whether the BP approach would perform good in a setting where there is no aggregate comovement in reality.

The core structure of the DGP consists of the following social planner's problem:

$$
\begin{gathered}
\max \sum_{t=0}^{\infty} \beta^{t} E_{0}\left(\ln \left(C_{t}-b C_{t-1}\right)-\psi \frac{N_{t}^{1+1 / \eta}}{1+1 / \eta}\right) \\
\text { s.t. } \\
K_{t}=(1-\delta) K_{t-1}+\left(1-\phi\left(\frac{I_{t}}{I_{t-1}}\right)\right) I_{t}
\end{gathered}
$$


Table 1: Specification of TFP

\begin{tabular}{c|c|c}
\hline \hline Specification & $X_{t}$ & $A_{t}$ \\
\hline 1 & $X_{t}=1$ & $\log A_{t}=\gamma_{A}+\log A_{t-1}+\varepsilon_{t}^{s, A}$ \\
2 & $X_{t}=\rho_{X} X_{t-1}+\varepsilon_{t}^{X}$ & $\log A_{t}=\gamma_{A}+\log A_{t-1}+\varepsilon_{t-q}^{n, A}$ \\
3 & $X_{t}=1$ & $\log A_{t}=\gamma_{A}+\log A_{t-1}+\varepsilon_{t}^{s, A}+\varepsilon_{t-q}^{n, A}$ \\
4 & $X_{t}=\rho_{X} X_{t-1}+\varepsilon_{t}^{X}$ & $\log A_{t}=\gamma_{A}+\log A_{t-1}+\varepsilon_{t}^{s, A}+\varepsilon_{t-q}^{n, A}$ \\
\hline
\end{tabular}

$$
\begin{gathered}
Y_{t}=T F P_{t} K_{t-1}^{\theta} N_{t}^{1-\theta} \\
Y_{t}=C_{t}+I_{t}+G_{t} \\
G_{t}=g_{t} Y_{t} .
\end{gathered}
$$

Here, $C_{t}, N_{t}, K_{t}, I_{t}, Y_{t}$ and $G_{t}$ stand for consumption, labor, capital, investment, output and government spending, respectively. $T F P_{t}$ and $g_{t}$ are exogenous processes for the level of technology and the share of government spending in total output, respectively. I assume that $g_{t}$ follows a stationary process subject to surprise and anticipated shocks,

$$
\ln g_{t}=(1-\rho) \ln \bar{g}+\rho_{g} \ln g_{t-1}+\varepsilon_{3, t}+\varepsilon_{4, t-q}
$$

$q$ denoting the anticipation lead. I set $q=2$, i.e., the anticipation lead is 2 quarters in this framework, since the calibration of the model corresponds to quarterly data.

I postulate the TFP in general form as

$$
T F P_{t}=X_{t} A_{t}
$$

where $X_{t}$ and $A_{t}$ constitute the temporary and permanent components of it, respectively. This TFP specification resembles very much the one in the seminal paper of King, Plosser, and Rebelo (1988a). Note that TFP is a unit root process in all forthcoming exercises, i.e., it has a permanent component. I consider four different specifications of TFP, of which components are summarized in Table 1. The implication of each specification for the success of the BP news shock identification approach is discussed below.

The values given in Table 2 are used for the parameters and mostly follow Barsky and 
Table 2: Calibration of DGP Parameters

\begin{tabular}{|c|c|c|c|c|c|c|c|c|c|c|}
\hline$\beta$ & $b$ & $\psi$ & $\eta$ & $\delta$ & $\theta$ & $\bar{g}$ & $\rho_{X}$ & $\gamma_{A}$ & $\phi^{\prime \prime}\left(\gamma_{A}\right)$ & $\sigma_{\varepsilon_{3}}=\sigma_{\varepsilon_{4}}$ \\
\hline 0.99 & 0.8 & 1 & 1 & 0.025 & 0.33 & 0.2 & 0.95 & 0.0025 & 0.3 & 0.25 \\
\hline
\end{tabular}

Sims (2011). $\sigma_{x}$ stands for the standard deviation of the term $x$. The standard deviations of the shocks affecting the TFP are reported below.

\subsection{Simulation Results}

Using the foregoing DGP, I generate 500 replications of time series with a sample length of 200 periods (quarters). I then compute the statistics of interest for each replication. Note that I replace $s p_{t}$ with the log of consumption $\left(c_{t}\right)$ in my simulations. The trivariate model additionally contains labor, $n_{t}$, and the four-variable model furthermore output, $y_{t}$, both in logs. Since labor is a stationary series by construction, including it in the VAR amounts having one additional, trivial cointegrating relation with a one corresponding to $n_{t}$ and zeros corresponding to the other variables. $c_{t}$ and $y_{t}$ are also cointegrated with $t f p_{t}$ by construction. Therefore, the cointegration rank is always set to $K-1$ in the $K$-variable models in the forthcoming exercises.

\subsubsection{TFP Specification 1}

The first TFP specification in Table 1 provides a means to check to what extent the BP scheme might artificially generate a high positive correlation between $\varepsilon_{2, t}$ and $\tilde{\varepsilon}_{1, t}$, although the two must be orthogonal to each other according to the true DGP. With this TFP specification, solely permanent surprise technology shocks impact on TFP. In this case, the short-run and long-run impact of shocks on the bivariate system read

$$
\Phi(0)=\left[\begin{array}{ll}
* & 0 \\
* & *
\end{array}\right] \text { and } \Phi(1)=\left[\begin{array}{cc}
* & 0 \\
* & 0
\end{array}\right]
$$

in terms of the representation given by (3), with consumption here being the second variable of the system instead of stock price. Note that in this case $\varepsilon_{2, t}$ is supposed to be a linear 
combination of the shocks to government spending share in GDP, and $\tilde{\varepsilon}_{1, t}$ stands for the only technology shock. It is hence expected that

$$
\varepsilon_{t}^{s, A}=\varepsilon_{1 t}=\tilde{\varepsilon}_{1, t} \text { and } \varepsilon_{2 t} \perp \tilde{\varepsilon}_{1, t}
$$

in terms of the BP schemes.

The experiment I conduct with the DGP under the first TFP specification shows that the $\mathrm{BP}$ scheme is successful in obtaining a low correlation between $\varepsilon_{2, t}$ and $\tilde{\varepsilon}_{1, t}$. Histograms corresponding to the measured correlation for the bivariate, trivariate and four-variable BP models are illustrated in the first, second and third columns of Figure 1, respectively. The first row of the figure corresponds to the correlation between $\varepsilon_{2, t}$ and $\tilde{\varepsilon}_{1, t}$ in the empirical models. According to the first histogram that corresponds to the bivariate model, for example, the correlation between $\varepsilon_{2, t}$ and $\tilde{\varepsilon}_{1, t}$ is between -0.2 and 0.2 in about $60 \%$ of the simulations; it is between -0.4 and 0.4 in about $90 \%$ of all simulations. ${ }^{12}$ The probability of a very low, statistically insignificant, correlation decreases somewhat with the number of variables included in the model. This may have to do with properties of the DGP which I do not deal with further in this paper. However, it is very unlikely that the correlation is above 0.8 for any model according to my simulations. Only the four-variable model generates a correlation coefficient above 0.8 in less than $10 \%$ percent of all simulations. It should be noted, however, that the four-variable model is subject to stochastic singularity, since there are only three shocks in the true DGP in this first exercise. Adding a further shock to the DGP would improve the performance of the four-variable model by enabling it to better isolate different shocks. In general, I conclude, the BP approach would very probably not obtain a high correlation between $\varepsilon_{2, t}$ and $\tilde{\varepsilon}_{1, t}$ if those were not highly correlated in reality.

I next turn to the success of the short-run identification scheme in obtaining an empirical "news" shock that is orthogonal to the true surprise technology shock, $\varepsilon_{t}^{s, A}$, and of the long-run scheme in recuperating the true and only technology shock $\varepsilon_{t}^{s, A}$. According to the second row of Figure 1, all short-run schemes are highly successful in obtaining of a very

\footnotetext{
${ }^{12}$ Note that I impose the sign restriction on both $\varepsilon_{2, t}$ and $\tilde{\varepsilon}_{1, t}$ that they correspond to a shock with a positive long-run impact on TFP in the simulations. Therefore, the majority of the correlations that are reflected in Figure 1 are positive.
} 
low, virtually zero, correlation between $\varepsilon_{2, t}$ and $\varepsilon_{t}^{s, A}$, and all long-run schemes are highly successful in obtaining a very high, i.e. above 0.8 , correlation between $\tilde{\varepsilon}_{1, t}$ and $\varepsilon_{t}^{s, A}$, as expected. It must be noted, however, that the success of the long-run schemes deteriorates gradually with the number of additional variables included in the VAR.

\subsubsection{TFP Specification 2}

After establishing that a Type I error is unlikely to be made by the BP schemes under Specification 1 and the probability of a Type II error also relatively low, I now turn to the specifications which are more in line with the premises of BP. Specification 2 in Table 1 describes the setting which was introduced at the beginning of Section 2. In the short run TFP is hit only by the temporary shock, $\varepsilon_{t}^{X}$, while only the anticipated technology shock,

$\varepsilon_{t}^{n, A}$, can have a long-run impact on it. For such a setting, histograms corresponding to the measured correlation across true and empirical shocks are illustrated in Figure 2. The first row again corresponds to the empirical correlation between $\varepsilon_{2, t}$ and $\tilde{\varepsilon}_{1, t}$, and the bivariate model is, again, the best performer in finding that correlation, which is supposed to be 1 according to the underlying DGP: in slightly more than $80 \%$ of all the simulations, it obtains a correlation coefficient that exceeds 0.8 . The probability of the correlation coefficient being above 0.6 is almost $100 \%$.

The success of the BP approach in obtaining a high correlation between $\varepsilon_{2, t}$ and $\tilde{\varepsilon}_{1, t}$ somewhat diminishes with trivariate and four-variable models. The latter models find a correlation coefficient above 0.8 in only about $70 \%$ of all simulations. This finding may at least partly be due to the fact that the trivariate and four-variable SR identification schemes do not exactly reflect the DGP. Notably, both (12) and (14) imply that there are two shocks with a possible non-negative impact on TFP in the long run according to the trivariate and four-variable SR schemes. The DGP with TFP Specification 2 foresees, on the other hand, that the second shock - the news shock - were the only long-run driving force of the TFP. Thus, the success of the SR identification scheme can be said to be related to the extent to which the estimated long-run impact of the first shock on TFP is zero. Note that if the $(1,1)$ element of $\Gamma(1)$ were exactly zero in the trivariate and four-variable cases, this would imply that the entire first column of $\Gamma(1)$ were zero according to Proposition 1 , in line with 
the DGP.

The second and third rows of Figure 2 highlight a significant discrepancy between the performances of the short-run and long-run BP identification schemes. The SR scheme is more successful than the LR scheme in obtaining the true correlation between the true and empirically estimated anticipated technology shocks. In terms of the bivariate model, for example, the SR scheme obtains a correlation between $\varepsilon_{2, t}$ and $\varepsilon_{t}^{s, A}$ that exceeds 0.8 in all simulations, whereas only about $60 \%$ of all correlations between $\tilde{\varepsilon}_{1, t}$ and $\varepsilon_{t}^{s, A}$ following from the LR scheme are above 0.8. Furthermore, the performances of both SR and LR schemes deteriorate with more variables in the VAR.

That the SR and LR schemes perform differently is indeed in line with what Christiano, Eichenbaum, and Vigfusson (2007) report in a Monte Carlo study and may thus not be so surprising. Note that the finding may have important implications for the users of the BP sequential approach to technological news shock identification. The bivariate scheme can, for example, successfully recuperate the news shock in all cases, although the correlation test would indicate a strong correlation between $\varepsilon_{2, t}$ and $\tilde{\varepsilon}_{1, t}$, i.e. a coefficient above 0.8 , in only about $80 \%$ of all cases. Yet, the LR scheme shock is correlated with the true shock with a coefficient above 0.8 in only about $60 \%$ of all cases. Hence, it can be deduced, the correlation test might generate spurious results to some degree.

From Figure 3, which shows the mean response to a standard news shock and the corresponding sampling uncertainty for the BP models, follows that the bivariate models are again the best performers in terms of detecting the true responses of TFP and consumption. The bivariate models with both short-run and long-run restrictions capture the true response better than the higher dimensional ones on average. The higher dimensional models underestimate the true response for both TFP and consumption, and the underestimation is wider in the four-variable case than in the trivariate case. Another important observation is that the LR identification schemes are associated with a higher estimation uncertainty than the SR identification schemes, which is in line with the findings of Christiano, Eichenbaum, and Vigfusson (2007). 


\subsubsection{TFP Specifications 3 and 4}

The last two specifications that I list in Table 1 postulate two other convenient constellations for the TFP process. Specification 3 is the simpler one and distinguishes between two types of permanent technology shocks: surprise and anticipated. Note that such a structure would be in line with the alternative approaches to identification of technological news shocks in Beaudry and Lucke (2010) and Barsky and Sims (2011). Under this constellation, the short-run BP scheme is supposed to be in line with the TFP specification, while the long-run scheme mingles the two types of technology shocks: $\varepsilon_{t}^{s, A}$ and $\varepsilon_{t-q}^{n, A}$. Under specification 4 , on the other hand, both schemes mingle shocks: the short-run scheme $\varepsilon_{t}^{X, A}$ and $\varepsilon_{t}^{s, A}$ for the surprise technology shock; the long-run scheme $\varepsilon_{t}^{s, A}$ and $\varepsilon_{t-q}^{n, A}$. Yet, the SR schemes are still supposed to detect news shocks correctly.

Note that under both of the foregoing TFP specifications the success of the BP identification schemes with respect to technological news shocks depends on the relative size of shocks. With both TFP specifications 3 and 4, it is expected that

$$
\varepsilon_{2 t}=\varepsilon_{t-q}^{n, A} \text { and } \tilde{\varepsilon}_{1, t}=\varepsilon_{t}^{s, A}+\varepsilon_{t-q}^{n, A}
$$

so that the correlation between $\varepsilon_{2, t}$ and $\tilde{\varepsilon}_{1, t}$ is

$$
\operatorname{corr}\left(\varepsilon_{2, t}, \tilde{\varepsilon}_{1, t}\right)=\frac{\sigma_{\varepsilon^{n, A}}^{2}}{\sigma_{\varepsilon^{n, A}} \sqrt{\sigma_{\varepsilon^{s, A}}^{2}+\sigma_{\varepsilon^{n, A}}^{2}}} .
$$

Thus, with $\sigma_{\varepsilon^{s, A}}=0.66$ and $\sigma_{\varepsilon^{n, A}}=0.66$, the expected correlation is 0.71 in the benchmark simulations. The histograms in Figure 4, which shows histograms corresponding to the DGP with TFP Specification 3, point out for the bi- and trivariate models that there is more than $50 \%$ probability of the correlation lying between 0.6 and 0.8 , the trivariate model being slightly more successful than the bivariate model. For the four-variable model, the probability of the correlation coefficient being between 0.6 and 0.8 is somewhat lower, but still close to $50 \%$. Yet, for all models, particularly for the bivariate and four-variable models, there is a non-negligible probabality - between $20 \%$ and $35 \%$ - that the correlation would be above 0.8 . Thus, there is a fairly high chance of the correlation test indicating, falsely, a too 
high correlation.

Particularly the bivariate and trivariate models with short-run restrictions are rather successful in recuperating the news shocks from the data if the third TFP specification underlies the DGP, see the second row of Figure 4. Both models generate a correlation between $\varepsilon_{2, t}$ and $\varepsilon_{2, t}^{n, A}$ above 0.8 in $80 \%$ of simulations. The four-variable model is yet less successful: it generates a correlation above 0.8 in only half of all simulations.

Finally, the long-run identification schemes are expected to generate a correlation of 0.71 between $\tilde{\varepsilon}_{1, t}$ and $\varepsilon_{2, t}^{n, A}$ by construction. The bi- and trivariate models can achieve this in roughly half and the four-variable model in only $35 \%$ of all simulations. Thus, LR schemes once again underperform SR schemes in recuperating the true shocks. The most striking finding for this paper though is that the probability of the LR scheme of generating a correlation between $\tilde{\varepsilon}_{1, t}$ and $\varepsilon_{2, t}^{n, A}$ that exceeds 0.8 is virtually zero with the bi- and trivariate models, and less than 10\% with the four-variable model. Yet, despite this finding, the BP correlation test would point to a too high positive correlation, i.e. above 0.8 , between $\varepsilon_{2, t}$ and $\tilde{\varepsilon}_{1, t}$ way too often. This, like under DGP with TFP Specification 2, suggests that the correlation diagnostic test might partly generate spurious results.

The importance of the relative size of shocks in the DGP for the success of a VAR identification scheme has often been emphasized in the VAR literature. ${ }^{13}$ In order to examine the relevance of the issue, I decrease the standard deviation of the surprise technology shock in the TFP Specification 3 by half to 0.33 in an alternative simulation. The histograms corresponding to this exercise are reported in Figure 5. As for the short-run identification schemes, it is eye-catching that the histograms for the relationship between $\varepsilon_{2, t}$ and $\varepsilon_{2, t}^{n, A}$ are very similar to the ones from the exercise with the TFP Specification 2. For the LR schemes, it must first be noted that the expected correlation between $\tilde{\varepsilon}_{1, t}$ and $\varepsilon_{2, t}^{n, A}$ is 0.89 with $\sigma_{\varepsilon^{s, A}}=0.33$. Almost all simulation correlations for the bi- and trivariate models with long-run restrictions lie between 0.6 and 1 , and, thus, these models can be said to be successful in capturing the properties of the true DGP. The four-variable model, albeit less succesfull, still captures a correlation between $\tilde{\varepsilon}_{1, t}$ and $\varepsilon_{2, t}^{n, A}$ that lies between 0.6 and 1 in

\footnotetext{
${ }^{13}$ See, e.g., Erceg, Guerrieri, and Gust (2005), Christiano, Eichenbaum, and Vigfusson (2007), Sims (2012) and Fève and Jidoud (2012).
} 
about $75 \%$ of all simulations. Finally, all models obtain a correlation between $\varepsilon_{2, t}$ and $\tilde{\varepsilon}_{1, t}$ that is above 0.8 with a high probability. Yet, as I argued above, some of these correlations might be of a spurious nature, since the models with LR restrictions are themselves not so successful in obtaining the true correlation between own long-run technology shocks and the news shock from the DGP.

To gain more insight into the identification performance of the BP schemes under the third TFP specification, I now turn to the responses of TFP and consumption to a onestandard-deviation news shock, illustrated in Figure 6 for both of the foregoing paratemer constellations. Note that the IRFs of the LR schemes cannot reflect the true responses to a news shock by construction as long as $\sigma_{\varepsilon^{s, A}} \neq 0$ but converge to it as $\sigma_{\varepsilon^{s, A}} \rightarrow 0$. The IRFs in the upper (lower) block correspond to the experiment with the higher (lower) standard deviation of technology shocks, i.e. $\sigma_{\varepsilon^{s, A}}=0.66\left(\sigma_{\varepsilon^{s, A}}=0.33\right)$. In the benchmark experiments with $\sigma_{\varepsilon^{s, A}}=0.66$, the SR schemes outperform the LR schemes both in terms of obtaining the true response on average and generating a smaller sampling uncertainty interval. Moreover, the LR schemes generally fail to include the true response within the sampling uncertainty interval at short horizons. The failure of the LR schemes disappears, however, when the standard deviation of the surprise technology shock is decreased by half to 0.33 . The LR schemes become partly even more successful than SR schemes in obtaining the true response on average when the standard deviation of the surprise technology shock is decreased, although they are still associated with relatively higher estimation uncertainty. The performance of the short-run schemes is less affected by the change in the standard deviation of the surprise technology shock. Finally, it must also be noted that both identification schemes are generally quite successful in recuperating the shape of the impulse response functions.

I do not report here the results from the experiments with the last TFP specification in Table 1, since those are very similar to the foregoing ones with TFP Specification 4. Hence, it can be claimed that some more noise through a temporary component in the TFP has a negligible impact on the identification of news shocks with the BP schemes. 


\section{Concluding Remarks}

In this paper, I have investigated the technical properties of the sequential approach implemented by Beaudry and Portier (2006) for identifying anticipated technology - the socalled news - shocks in the SVAR framework. I have examined to extent to which the BP approach could be empirically successful in recuperating news shocks with technology content from the data by means of a Monte Carlo experiment. Thereby, I used the neoclassical growth model with real frictions as the data generating process and considered various alternative specifications for TFP, a crucial variable when identifying anticipated technology shocks, which are widely used in the existing literature.

My general finding is that the BP approach, even with a small VAR model with only two variables, can be quite successful in estimating the news shocks and their dynamic multipliers. It often obtains a high correlation between long-run technology shocks and news shocks when the true DGP is constructed in that way. However, the sequential approach may also partly generate spuriously high correlations between the short-run news and long-run technology shocks. Nevertheless, the approach would not generate a high correlation between the foregoing shocks, were these not strongly correlated in the underlying true DGP.

Another relevant finding is that the performances of short-run and long-run BP identification schemes differ in terms of recuperating the true anticipated technology shock series. Yet, both schemes typically deliver very similar average impulse response functions with respect to these shocks, although the long-run schemes are typically associated with higher estimation uncertainty than short-run schemes.

All in all, the sequential BP approach is a useful tool for estimating news shocks with technology content. On the contrary to what Sims (2012) suggests for the identification scheme of Barsky and Sims (2011), that using more forward-looking variables than just stock price might lead to better results, low dimensional BP models could perform rather good in recuperating the technological news shocks.

Note that, while the sequential approach provides one way of estimating the technology content of news shocks, other possibilities to explore the validity of the technology interpretation of news shocks exist as well. Haertel and Lucke (2008) and Lucke (2013) use, for 
example, patent data and test whether those are Granger-causal for news shocks in the US and Germany. The authors establish both a significant technology content of news shocks and a significant role for them in the short-run macroeconomic fluctuations of the two countries. My findings can be seen as complementary to the findings of these authors, since they are supportive for the technology interpretation of Beaudry and Portier (2006), who also report a significant role for technological news shocks in the US business cycles.

\section{References}

Barsky, R. B., and E. R. Sims, 2011, "News Shocks and Business Cycles," Journal of Monetary Economics, 58(3), 273-289.

Beaudry, P., and B. Lucke, 2010, "Letting Different Views about Business Cycles Compete," in NBER Macroeconomics Annual 2009, ed. by D. Acemoglu, K. Rogoff, and M. Woodford, vol. 24 , pp. 491-494.

Beaudry, P., and F. Portier, 2006, "Stock Prices, News, and Economic Fluctuations," American Economic Review, 96(4), 1293-1307.

Beaudry, P., F. Portier, and A. Seymen, 2013, "Comparing Two Methods for the Identification of News Shocks," ZEW Discussion Papers 13-110.

Chari, V., P. J. Kehoe, and E. R. McGrattan, 2008, "Are Structural VARs with LongRun Restrictions Useful in Developing Business Cycle Theory?," Journal of Monetary Economics, 55(8), 1337-1352.

Christiano, L. J., M. Eichenbaum, and R. Vigfusson, 2007, "Assessing Structural VARs," in NBER Macroeconomics Annual 2006, ed. by D. Acemoglu, K. Rogoff, and M. Woodford, vol. 21, pp. 1-106.

Erceg, C. J., L. Guerrieri, and C. Gust, 2005, "Can Long-Run Restrictions Identify Technology Shocks?," Journal of the European Economic Association, 3(6), 1237-1278. 
Fernández-Villaverde, J., J. F. Rubio-Ramírez, T. J. Sargent, and M. W. Watson, 2007, “ABCs (and Ds) of Understanding VARs," American Economic Review, 97(3), 1021-1026.

Fève, P., and A. Jidoud, 2012, "Identifying News Shocks from SVARs," Journal of Macroeconomics, 34(4), 919-932.

Fève, P., J. Matheron, and J.-G. Sahuc, 2009, "On the Dynamic Implications of News Shocks," Economics Letters, 102(2), 96-98.

Forni, M., L. Gambetti, and L. Sala, 2011, "No News in Business Cycles," CEPR Discussion Papers 8274.

Haertel, T., and B. Lucke, 2008, "Do News Shocks Drive Business Cycles? Evidence from German Data," Economics - The Open-Access, Open-Assessment E-Journal, 2(10).

King, R. G., C. I. Plosser, and S. T. Rebelo, 1988a, "Production, Growth and Business Cycles I. The Basic Neoclassical Model," Journal of Monetary Economics, 21, 195-232.

— , 1988b, "Production, Growth and Business Cycles II. New Directions," Journal of Monetary Economics, 21, 309-341.

King, R. G., C. I. Plosser, J. H. Stock, and M. W. Watson, 1991, "Stochastic Trends and Economic Fluctuations," American Economic Review, 81(4), 819-840.

Leeper, E. M., T. B. Walker, and S.-C. S. Yang, 2009, "Fiscal Foresight and Information Flows," NBER Working Papers 14630.

Lucke, B., 2013, "Testing the technology interpretation of news shocks," Applied Economics, $45(1), 1-13$.

Lütkepohl, H., 2005, New Introduction to Multiple Time Series Analysis. Berlin: SpringerVerlag.

Schmitt-Grohé, S., 2009, "Paul Beaudry and Bernd Lucke: 'Letting Different Views about Business Cycles Compete,"' in NBER Macroeconomics Annual 2009, ed. by D. Acemoglu, K. Rogoff, and M. Woodford, vol. 24. 
Sims, E., 2012, "News, Non-Invertibility, and Structural VARs," Advances in Econometrics, $28,81-136$.

Vukotić, M., 2013, "A Sectoral Approach to News Shocks," mimeo, University of Warwick. 
Figure 1: Histogram of Correlations under TFP Specification 1

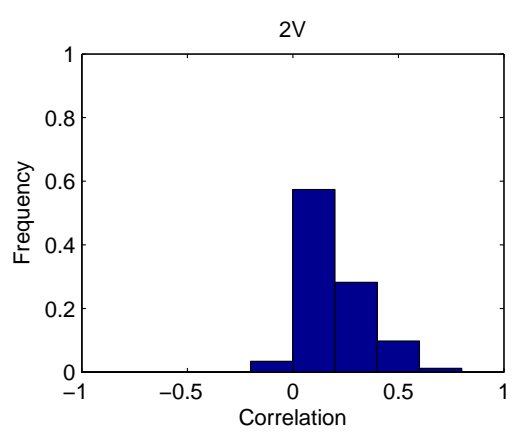

Correlation between $\varepsilon_{2, t}$ and $\tilde{\varepsilon}_{1, t}$
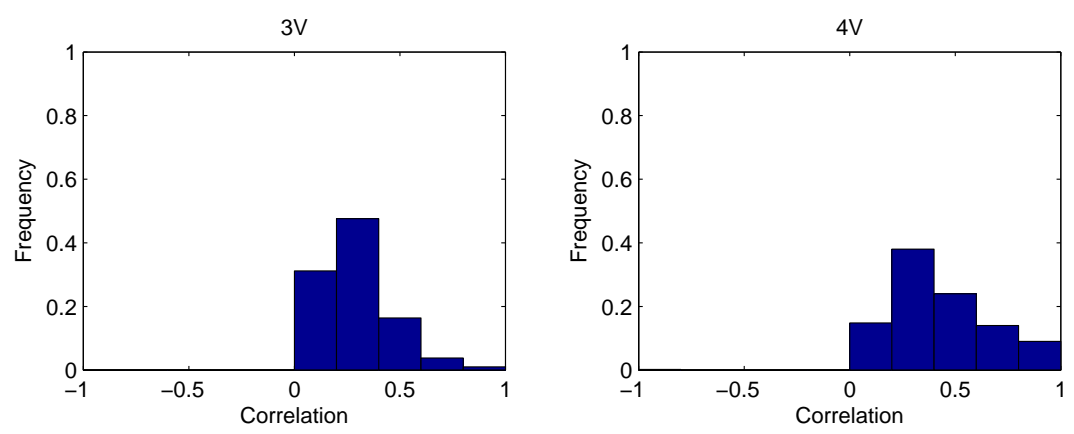

Correlation between $\varepsilon_{2, t}$ and $\varepsilon_{t}^{s, A}$
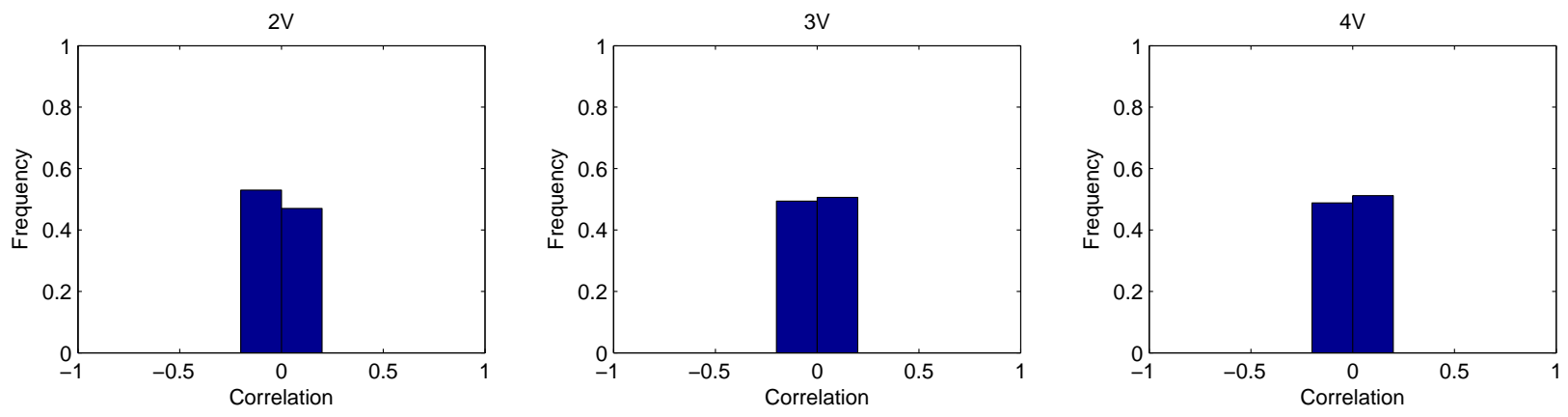

Correlation between $\tilde{\varepsilon}_{1, t}$ and $\varepsilon_{t}^{s, A}$
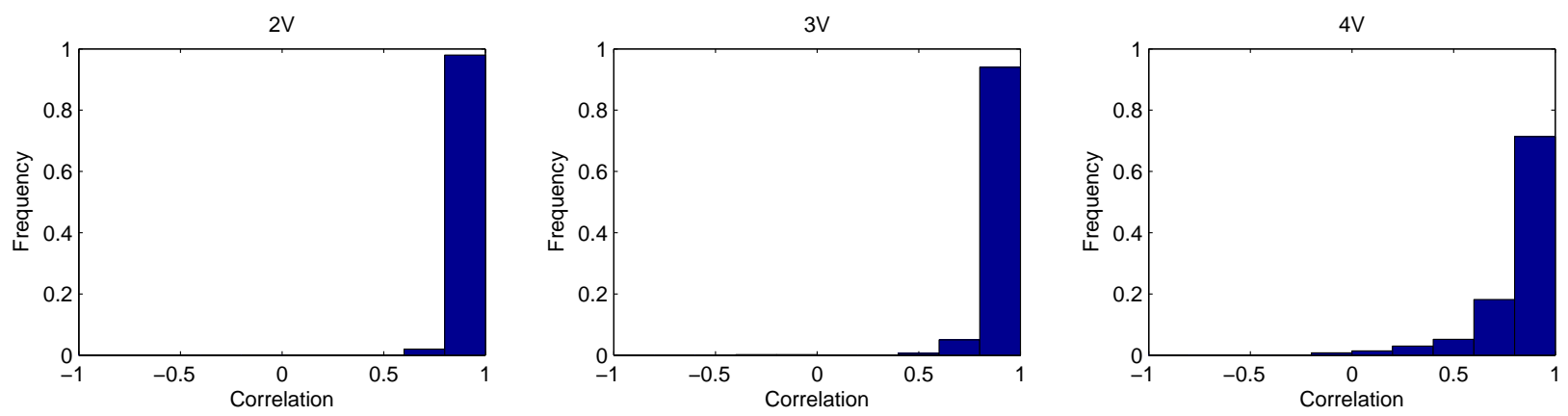

Notes: Share of correlation coefficients falling in a certain interval in the simulation is shown. The generic mnemonic " $\mathrm{xV}$ " in the graph titles refers to the $\mathrm{x}$-variable BP model. See Table 1 for the TFP specification. Standard deviation of shocks: $\sigma_{\varepsilon^{s}}=0.66$. 1st row: correlation between empirical shocks. 2nd and 3rd rows: correlation between the true technology shock and the empirical short-run "news" and long-run technology shock, respectively. 
Figure 2: Histogram of Correlations under TFP Specification 2

Correlation between $\varepsilon_{2, t}$ and $\tilde{\varepsilon}_{1, t}$
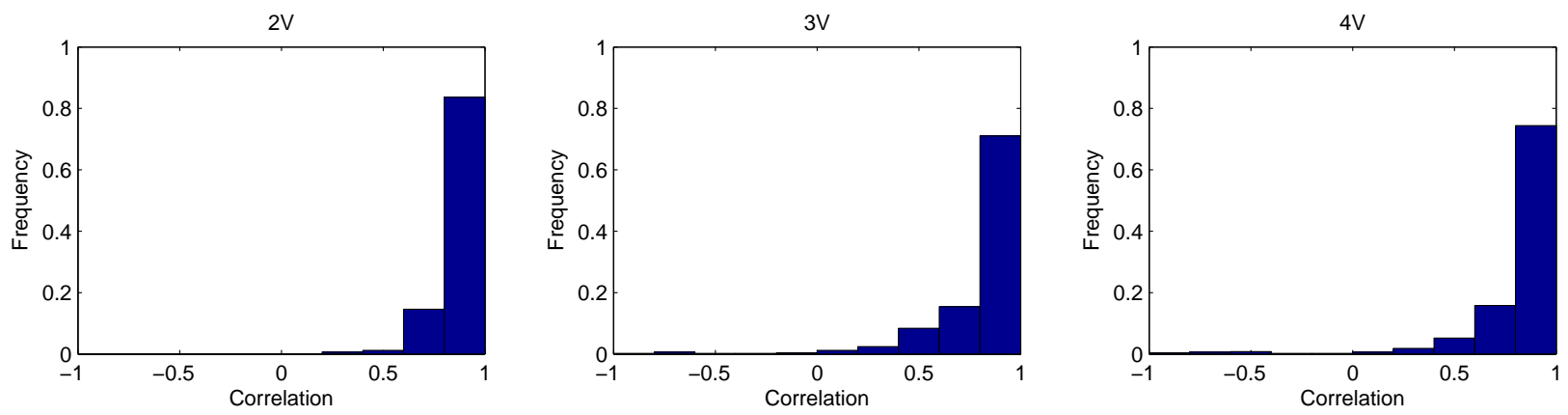

Correlation between $\varepsilon_{2, t}$ and $\varepsilon_{t}^{s, A}$
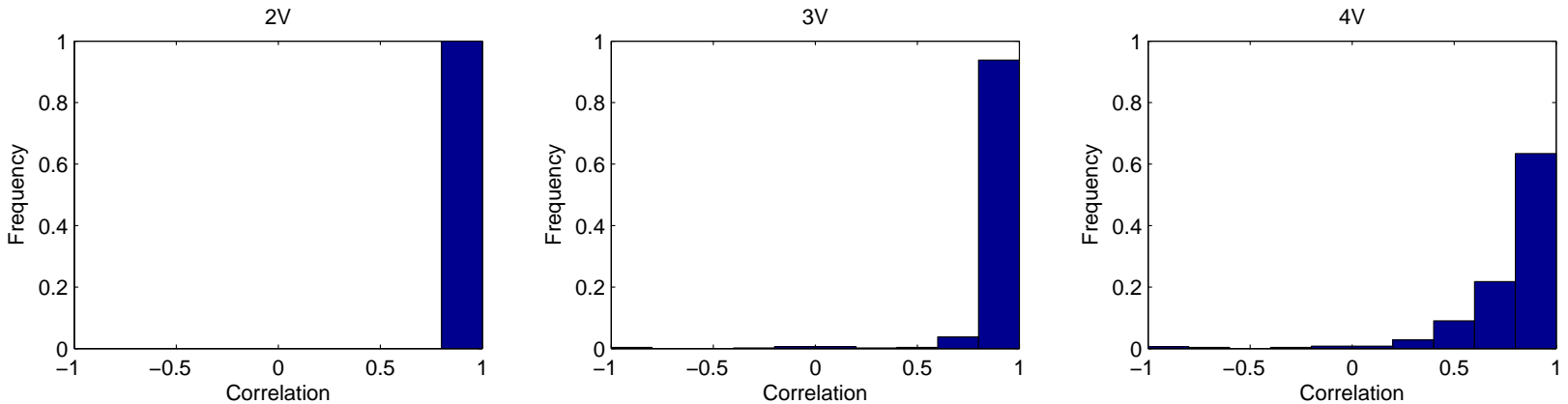

Correlation between $\tilde{\varepsilon}_{1, t}$ and $\varepsilon_{t}^{s, A}$
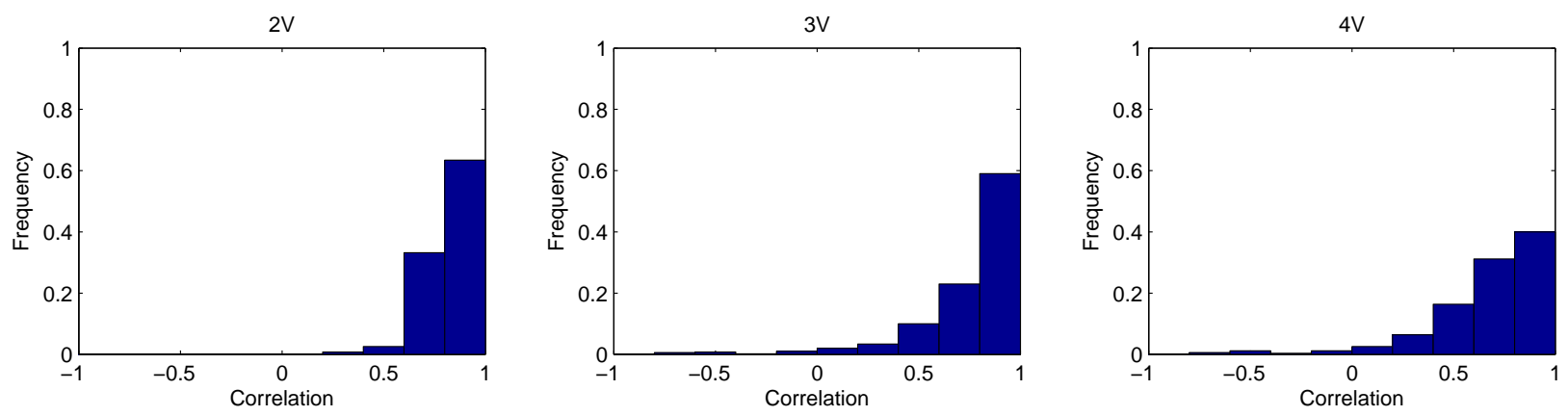

Notes: Share of correlation coefficients falling in a certain interval in the simulation is shown. The generic mnemonic " $\mathrm{x}$ " in the graph titles refers to the $\mathrm{x}$-variable BP model. See Table 1 for the TFP specification. Standard deviation of shocks: $\sigma_{\varepsilon^{x}}=0.66 . \sigma_{\varepsilon^{n, A}}=0.66$. 1st row: correlation between empirical shocks. 2nd and 3rd rows: correlation between the true technology/news shock and the empirical short-run news and long-run technology, respectively. 
Figure 3: Response to a News Shock under TFP Specification 2
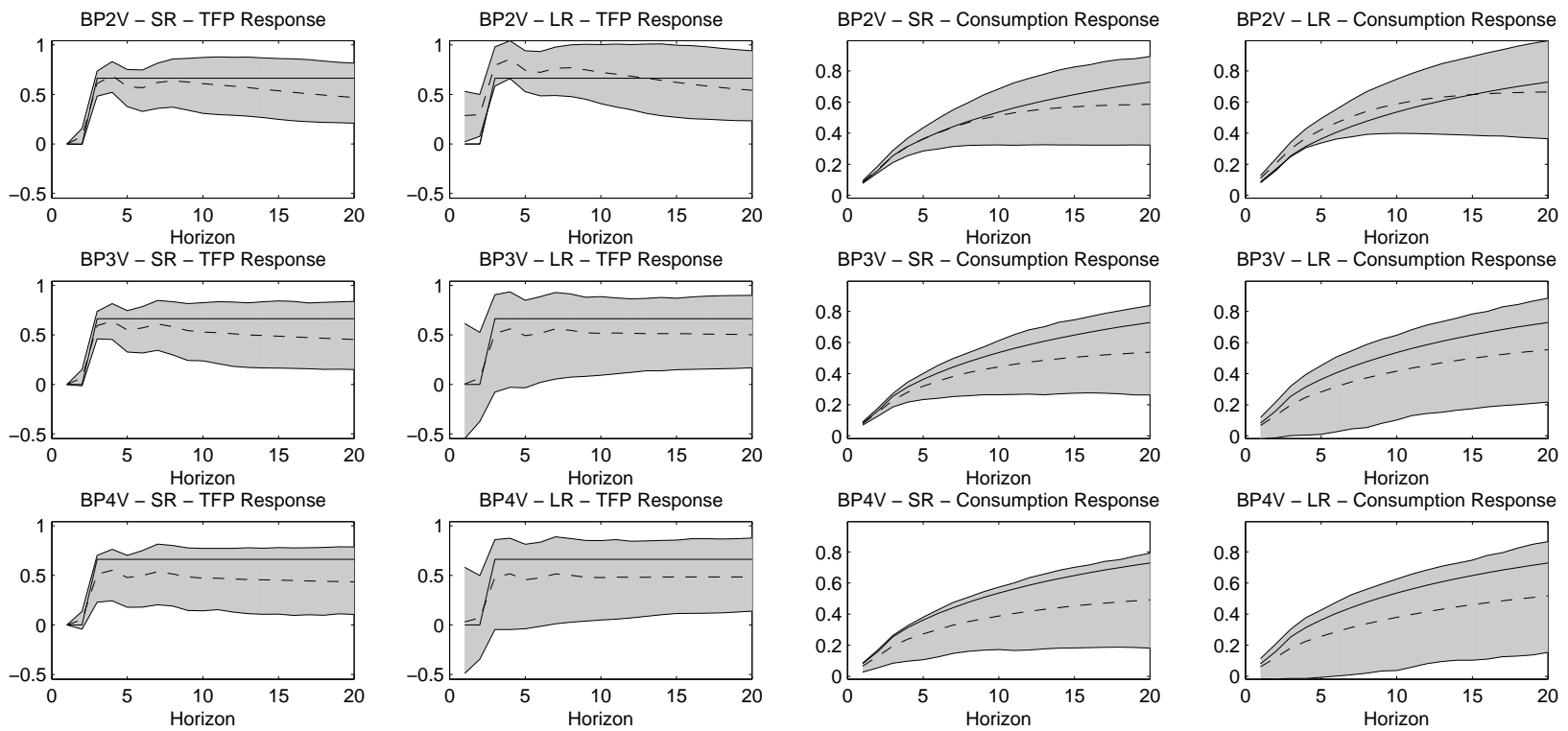

true - - - BP model

Notes: The generic mnemonic " $\mathrm{xV}$ " in the graph titles refers to the $\mathrm{x}$-variable $\mathrm{BP}$ model. See Table 1 for the TFP specification. The shaded area shows the $95 \%$ confidence band from 500 Monte Carlo simulations with a sample length of 200 periods. 
Figure 4: Histogram of Correlations under TFP Specification 3

Correlation between $\varepsilon_{2, t}$ and $\tilde{\varepsilon}_{1, t}$
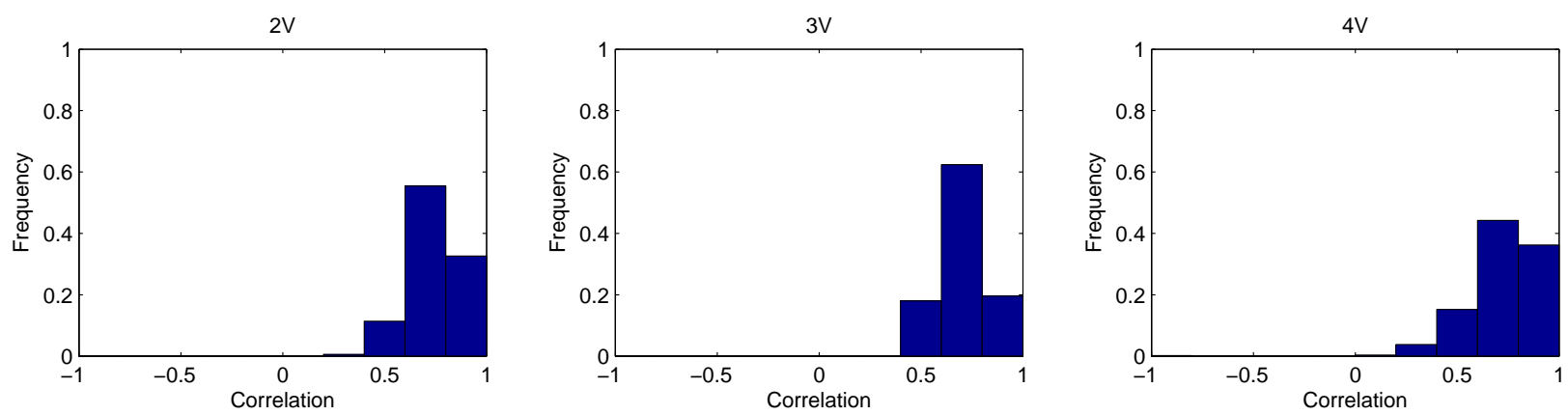

Correlation between $\varepsilon_{2, t}$ and $\varepsilon_{t}^{n, A}$
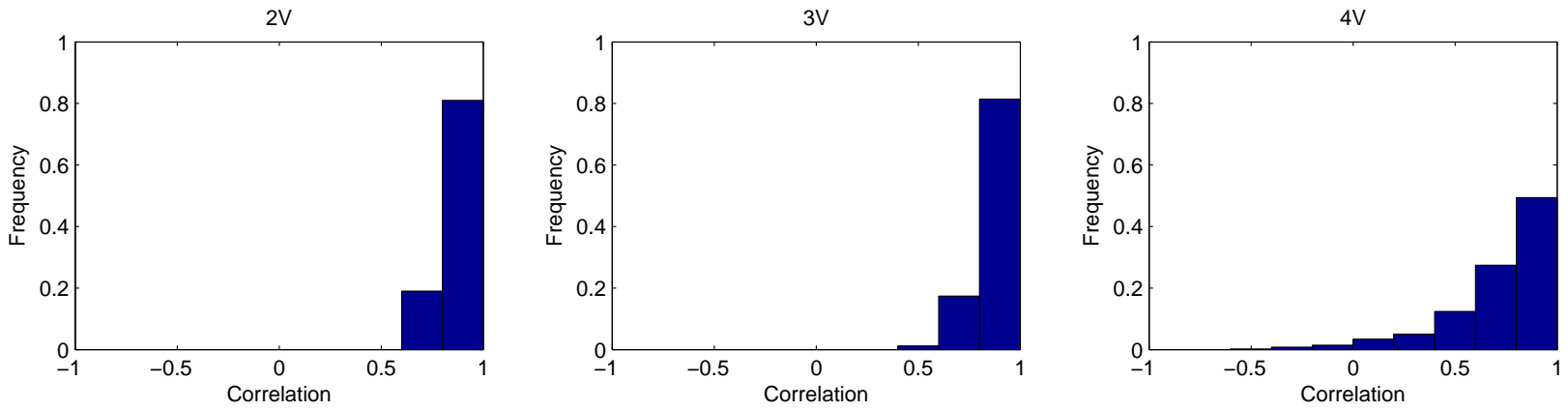

Correlation between $\tilde{\varepsilon}_{1, t}$ and $\varepsilon_{t}^{n, A}$
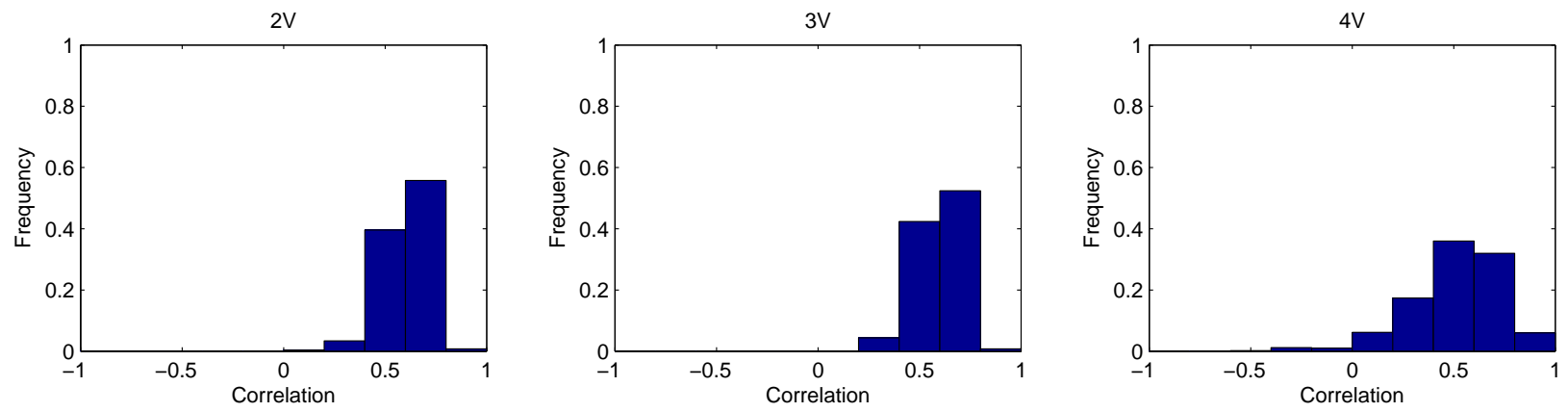

Notes: Share of correlation coefficients falling in a certain interval in the simulation is shown. The generic mnemonic " $\mathrm{xV}$ " in the graph titles refers to the $\mathrm{x}$-variable BP model. See Table 1 for the TFP specification. Standard deviation of shocks: $\sigma_{\varepsilon^{s, A}}=0.66$. $\sigma_{\varepsilon^{n, A}}=0.66$. 1st row: correlation between empirical shocks. 2nd and 3rd rows: correlation between the true news shock and the empirical short-run news and long-run technology shock, respectively. 
Figure 5: Histogram of Correlations under TFP Specification 3

Correlation between $\varepsilon_{2, t}$ and $\tilde{\varepsilon}_{1, t}$
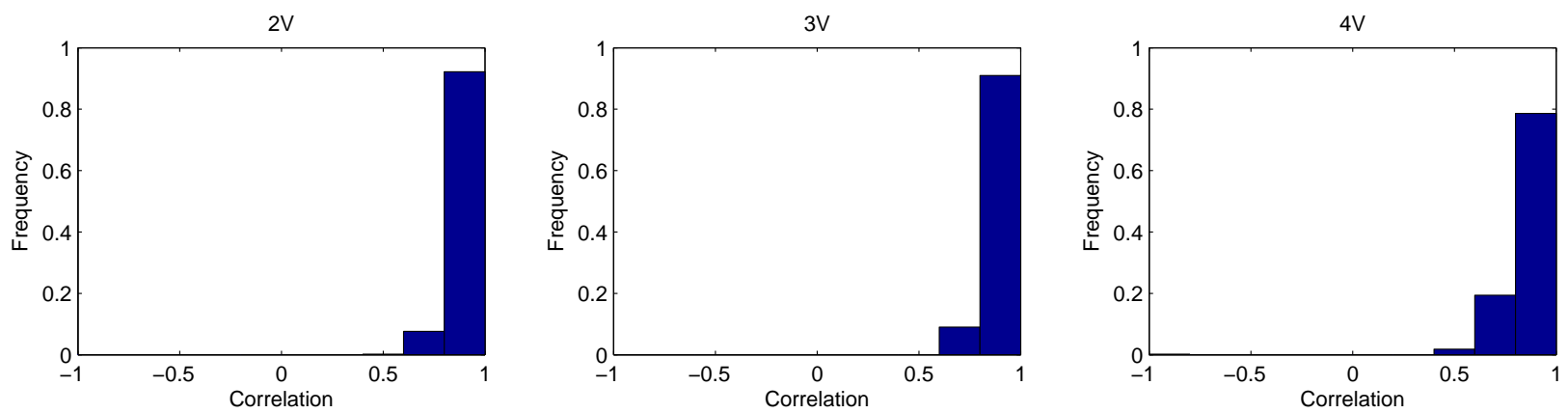

Correlation between $\varepsilon_{2, t}$ and $\varepsilon_{t}^{n, A}$
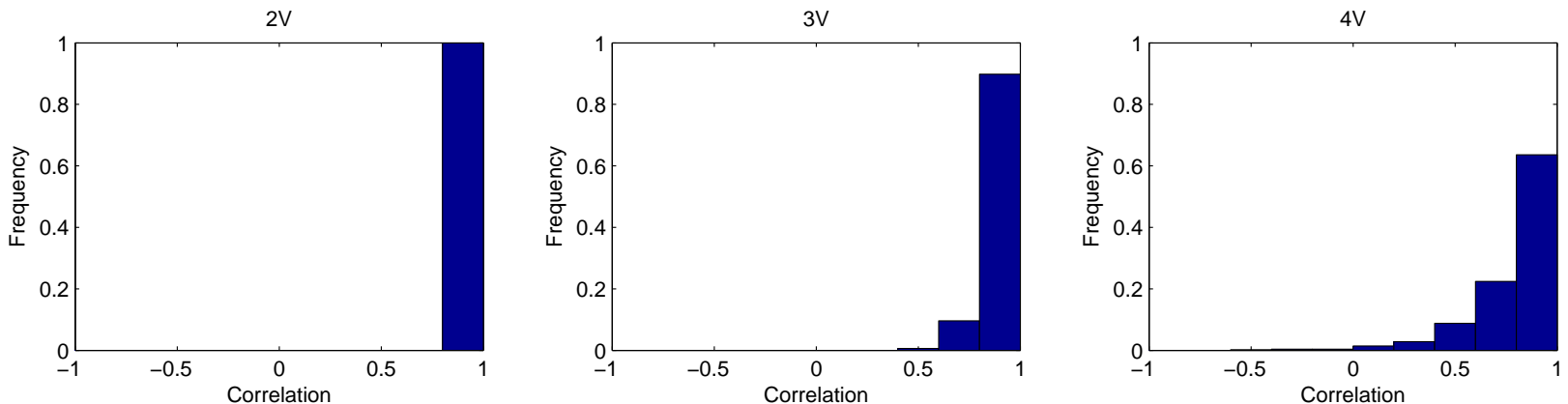

Correlation between $\tilde{\varepsilon}_{1, t}$ and $\varepsilon_{t}^{n, A}$
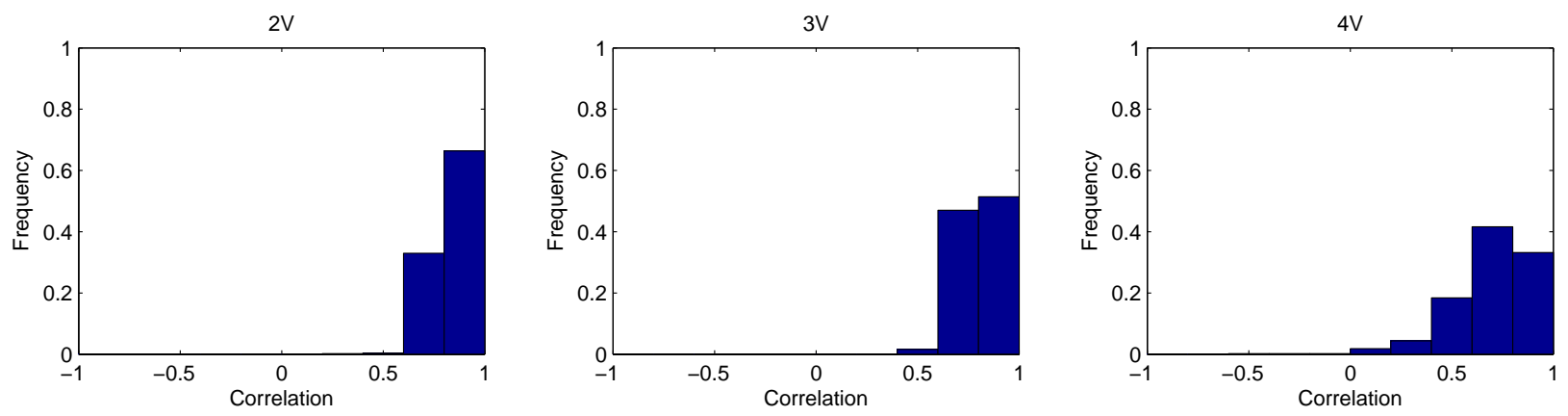

Notes: Share of correlation coefficients falling in a certain interval in the simulation is shown. The generic mnemonic " $\mathrm{xV}$ " in the graph titles refers to the $\mathrm{x}$-variable BP model. See Table 1 for the TFP specification. Standard deviation of shocks: $\sigma_{\varepsilon^{s, A}}=0.33 . \sigma_{\varepsilon^{n, A}}=0.66$. 1st row: correlation between empirical shocks. 2nd and 3rd rows: correlation between the true news shock and the empirical short-run news and long-run technology shock, respectively. The difference to the simulation in Figure 4 is that in the current figure $\sigma_{\varepsilon^{s, A}}=0.33$. 
Figure 6: Response to a News Shock under TFP Specification 3

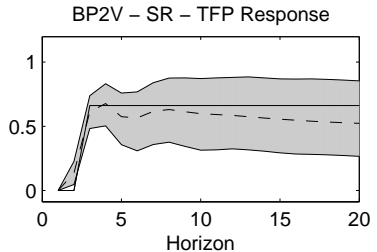

BP3V - SR - TFP Response

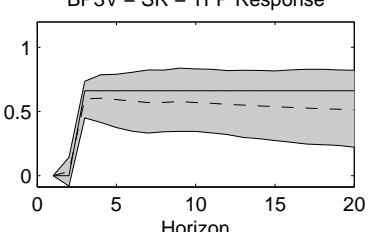

BP4V - SR - TFP Response

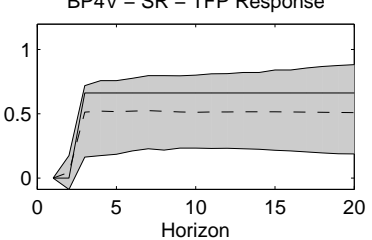

$$
\sigma_{\varepsilon^{s, A}}=0.66, \sigma_{\varepsilon^{n, A}}=0.66
$$
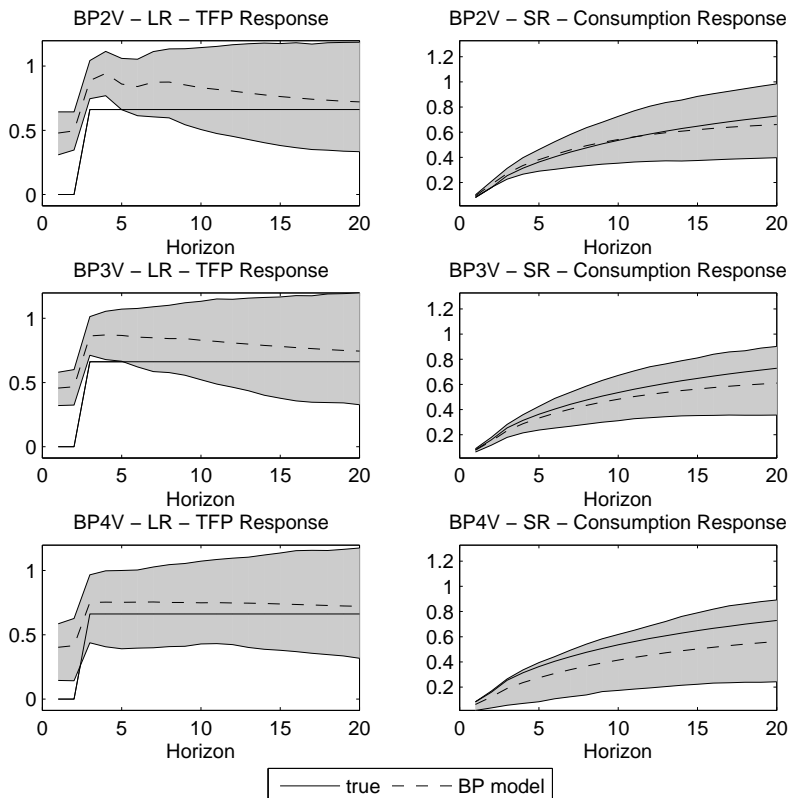

$$
\sigma_{\varepsilon^{s, A}}=0.33, \sigma_{\varepsilon^{n, A}}=0.66
$$
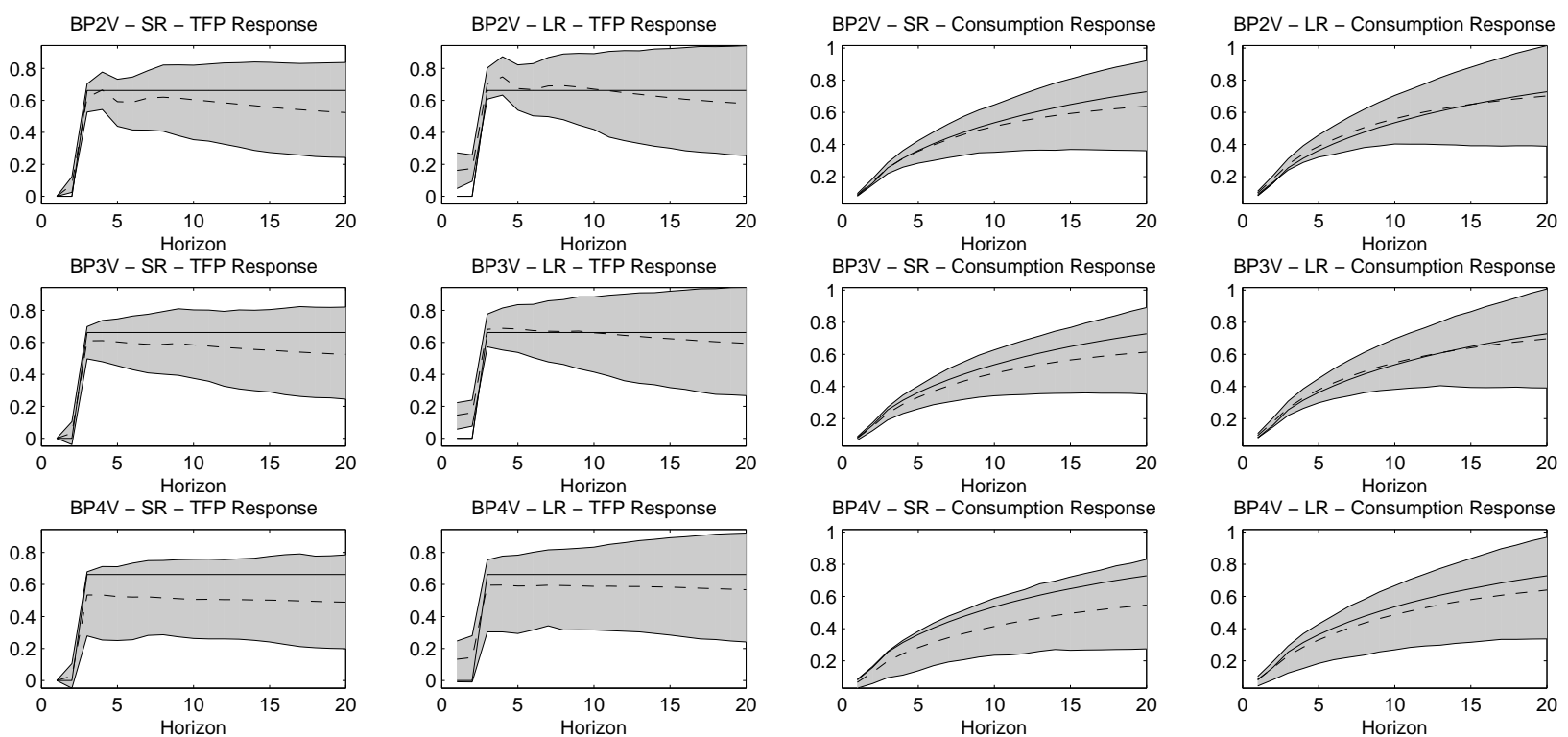

Notes: The generic mnemonic "xV" in the graph titles refers to the $\mathrm{x}$-variable $\mathrm{BP}$ model. See Table 1 for the TFP specification. The shaded area shows the $95 \%$ confidence band from 500 Monte Carlo simulations with a sample length of 200 periods. 


\section{Appendix: Proofs of Propositions}

Proof 1 (Proof of Proposition 1) It is known from the Granger representation theorem that the matrix of the long-run multipliers $C(1)$ has rank $K-r$. Note that $\tilde{\Gamma}(1)$ must have the same rank due to (10) and the fact that $\tilde{\Gamma}_{0}$ is non-singular by construction. Thus, $\tilde{\Gamma}(1)$ can be written as

$$
\tilde{\Gamma}(1)=\left[\begin{array}{ccc}
\tilde{\gamma}_{11} & \ldots & \tilde{\gamma}_{1 K} \\
\vdots & \ldots & \vdots \\
\tilde{\gamma}_{K-r, 1} & \ldots & \tilde{\gamma}_{K-r, K} \\
\kappa_{1}\left[\tilde{\gamma}_{11}, \ldots, \tilde{\gamma}_{K-r, 1}\right]^{\prime} & \ldots & \kappa_{1}\left[\tilde{\gamma}_{1 K}, \ldots, \tilde{\gamma}_{K-r, K}\right]^{\prime} \\
\vdots & \ldots & \vdots \\
\kappa_{r}\left[\tilde{\gamma}_{11}, \ldots, \tilde{\gamma}_{K-r, 1}\right]^{\prime} & \ldots & \kappa_{r}\left[\tilde{\gamma}_{1 K}, \ldots, \tilde{\gamma}_{K-r, K}\right]^{\prime}
\end{array}\right]
$$

where $\kappa_{i}$ for $i=1, \ldots, r$ are row vectors of length $K-r$. From (21) follows straightforward that the last $r$ elements of the $j^{\text {th }}$ column of $\tilde{\Gamma}(1)$ must be equal to zero, when the first $K-r$ elements of the same column are set to zero.

Proof 2 (Proof of Proposition 2) The Granger representation theorem states that the $r \times K$ matrix $\beta^{\prime}$ containing the cointegrating vectors is orthogonal to the matrix of long-run multipliers: $\beta^{\prime} C(1)=0_{r \times K}$. Hence,

$$
\beta^{\prime} \tilde{\Gamma}(1)=0_{r \times K}
$$

following from (10). Since $\tilde{\Gamma}(1)$ has a cointegration rank of $K-r$, i.e., $K-r$ independent elements in each of its columns, (22) amounts to $r(K-r)$ restrictions on each row of $\tilde{\Gamma}(1)$.

Let $\tilde{\Gamma}(1)$ be partitioned as

$$
\tilde{\Gamma}(1)=\left[\begin{array}{ll}
\hat{\Gamma}_{K \times(K-r)} & 0_{K \times r}
\end{array}\right]
$$

so that only the first $K-r$ shocks can have a permanent impact on the variables in this system. Note that the knowledge of the first $K-r$ columns of $\tilde{\Gamma}_{0}$ is necessary for computing the 
dynamic multipliers of the permanent shocks. Furthermore, the knowledge of the first $K-r$ rows of the matrix $\tilde{\Gamma}_{0}^{-1}$ is necessary for computing the variances of the permanent shocks. $K P S W$ show that the knowledge of either the first $K-r$ columns of $\tilde{\Gamma}_{0}$ or the first $K-r$ rows of $\tilde{\Gamma}_{0}^{-1}$ is enough for computing the other one. Thus, when the interest lies in computing the dynamics related to the permanent shocks, $K(K-r)$ elements of either $\tilde{\Gamma}_{0}$ or $\tilde{\Gamma}_{0}^{-1}$ have to be estimated. When the covariance matrix of structural shocks is an identity matrix, as has always been assumed in this note, this imposes $(K-r)((K-r)+1) / 2$ restrictions to this end. Recall from above that $r(K-r)$ additional restrictions come from the cointegration property of the model. Hence,

$$
K(K-r)-\frac{(K-r)((K-r)+1)}{2}-r(K-r)=\frac{(K-r)((K-r)-1)}{2}
$$

more restrictions are needed for computing the dynamic multipliers of the permanent shocks. 